\title{
Personal and Behavioral Peculiarities of Gifted Children: The Search for Invariant Characteristics of Giftedness*
}

\author{
Marina Ivleva \\ Department of Social Philosophy \\ Peoples' Friendship University of Russia \\ 6 Miklukho-Maklaya Str. \\ Moscow, Russia \\ E-mail: ivleva_ml@pfur.ru
}

\begin{abstract}
In this article the author makes an attempt to generalize and systematize, with the help of comparative and classification approaches, the data from the actual and actively developing in the modern social sciences field of experimental research of giftedness, which is aimed at searching for the basic characteristics of giftedness and creating a typical psychological portrait of a gifted child. The results of research of personal and behavioral peculiarities of gifted children both in comparison with peers and within a group of gifted children are presented.
\end{abstract}

Keywords-giftedness; personal characteristics; behavioral characteristics; invariant characteristics; typical psychological portrait; intragroup differences; intergroup differences

\section{INTRODUCTION}

In recent years, social science has developed an idea of giftedness as a complex, multilevel phenomenon, and its various components are still subject to experimental research due to unresolved questions about the interaction of the elements entering into the structure of giftedness, about the ratio of the age and individual in the development of giftedness, individual manifestations of giftedness, its different types and levels, the understanding of giftedness as a person's quality, the time of its beginning, rise and fall, as well as the speed of development and the dynamics of this process [1].

Achievements in the field of the study of giftedness can be assessed as rather modest. Many people see the reasons for this in the features of the subject of study, which, due to its extreme individualization, is difficult, and practically impossible to typify [2] [3] [4]. In other words, the data obtained as a result of the research contribute to the creation of a multicolored picture of giftedness, but they hardly advance the researchers in identifying the core, invariant characteristics of giftedness. For example, here is what the list of experimental developments of American National Research Center of Gifted and Talented (Javits Center) looks

* The publication has been prepared with the support of the "RUDN University Program 5-100". like:

- The study of the practice of teaching gifted children.

- The study of the contents of the programs of teaching gifted children.

- The study of the positive experience of teaching gifted children.

- The study of gifted students who have overcome difficulties in learning by the method of cases.

- Training to interact and gifted children.

- Longitudinal study of effective practices of teaching gifted children.

- Ethnographic study of the experience of higher education in the preparation of highly gifted students in the situation of urbanization.

- Studying the development of giftedness in economically disadvantaged students, as well as with limited experience (knowledge of English with a language barrier).

- Study of the results of training programs.

- Study of the methods and projects to identify gifted students and to evaluate programs for gifted children,

- Preparation of future teachers for work with gifted children.

- Social and emotional adaptation of gifted children.

- The START Project: a joint action of CharlotteMecklenburg schools to develop gifted children from national and racial minorities.

- A theorized approach to the identification, training and evaluation of gifted children.

- The motivation of insufficiently successful gifted adolescents from urban and suburban schools. 
As can be seen, the problematic of the research of gifted children is wide and varied. It should be mentioned that attention is drawn to many aspects of the study of giftedness, its various manifestations in the most diverse representatives of this category of trainees. The above list indicates that the problems of studying gifted children are far from being resolved. In particular, the issue of the possibility of typologizing gifted people, revealing stable features that distinguish these children from their peers remains a debatable topic.

Nevertheless, it should be noted that the research of giftedness at the present time makes it possible to obtain information about the characteristics of gifted children in comparison with their peers; the differences within this group of children; about the dynamics of indices of talent in different periods of ontogenetic development; the influence of cognitive and non-cognitive characteristics of the individual on the development of giftedness; the role of the social environment in the development of gifted children. The article attempts to generalize and systematize the data of the conducted research in order to create a typical psychological portrait of a gifted child on the basis of a comparative and classification approaches.

\section{INTERGROUP FEATURES OF GIFTED CHILDREN COMPARED WITH PEERS}

According to A.M. Matyushkin, gifted children are characterized by the following psychological qualities: pronounced research motivation (the need to search for cognitive and personal problems); exploratory creative activity aimed at finding and discovering something new; the ability to find a new solution to the problem, to express one's own new thought or to realize it in the form of an artistic, intellectual, material "product"; the ability to clearly express thoughts in words [5].

Most foreign concepts of giftedness (especially American) characterize it, as a rule, by the interaction of three parameters: advanced development of cognition, psychosocial development and physical data. The concretization of these parameters was obtained as a result of observations of gifted children, interviews with their parents and other adults involved in the learning and development process, generalization of experimental research data, and it looks as follows.

In the field of knowledge, gifted children are characterized by breadth of perception, curiosity, high research activity and distribution of attention. They have excellent memory, early language development, large vocabulary, freely and clearly state their thoughts, invent words, trace cause-effect relationships and easily cope with cognitive uncertainty. They are persistent in achieving results, are keenly interested, prefer games to activate mental abilities, but do not like the imposed ready answer.

The second parameter is the high psychosocial sensitivity of gifted children, which is manifested in a heightened sense of justice, outstripping moral development, lively and vivid imagination, rich fantasy, and a great sense of humor. They react sharply to injustice, respond vividly to the truth, love harmony and nature, raise high demands on themselves and others. There are cases of exaggerated fears, increased sensitivity to the non-verbal signals of others, extrasensory abilities. Some children develop negative self-perception and difficulties in communicating with their peers. The physical characteristics of gifted children are not so pronounced and relate mainly to the high energy level, vision problems up to 8 years, as well as the imbalance of motor coordination, since manual skills and coordination between visual perception and mechanical movement do not keep up with the high rate of development of cognitive abilities [6].

Traditionally, giftedness was identified by the rate of mental development or the degree of the child's advancement of his peers, other things being equal, in the intelligence quotient (IQ). It turned out that this quantitative indicator is not the only and decisive one. The criterion of creative potential was added to it.

Studies have made it possible to introduce some specifications and changes in the search for basic characteristics of giftedness. Thus, the results of the Moscow longitudinal study of mentally gifted students of 9-11 grades show that gifted students have a clear superiority in the indicators of all intellectual abilities and the speed of processing information. It is less noticeable in terms of creativity [7]. The differences in the motivational and personal sphere proved to be reliable, but they relate to the more expressed hope of gifted children for success and to the less pronounced fear of failure, greater stability of thinking under stress, high academic self-esteem, academic performance, activity in out-of-school life, mainly in the field of natural sciences and literature. There are no significant differences in overall self-esteem, anxiety, instability of thinking under stress, activity in sports, music, technology.

According to J. Renzulli, gifted adults are characterized by a combination of three parameters: intellectual abilities above the average, creative approach and perseverance. This description, in our opinion, can be fully applicable to holders of multilateral abilities [8].

L. Terman and M. Oden speak about such characteristics of gifted children as high learning outcomes, well developed abstract thinking, interest in reading biographies, reading skill before school, IQ above 130, ability to learn languages [9].

In the literature other characteristics of gifted people are also presented: idealism, perfectionism, increased sense of responsibility, speech and vocabulary, the ability at three years of age to follow two or more events around, low sleep duration, early numeracy or reading skill, quick perception and imagination, use of complex words.

A special area of research of giftedness is the study of creatively gifted people, their personal characteristics, products of their creativity and development opportunities. Most studies have established a certain stable set of personality traits of these people, which sometimes seem to be mutually exclusive. Thus, M. Chikszentmihalyi cites the following list of features of creative personalities: great 
physical energy, but they are often in a state of rest and relaxation; severity and naivety at the same time; a combination of playfulness and discipline, responsibility and irresponsibility; modesty and pride; rebelliousness and conservatism; notions, fantasies and a sense of reality alternate; they avoid stereotypes about sexual roles; they demonstrate a passion for work, but can also objectively evaluate its results; they are open and sensitive, they like pleasures; they show the characteristics of both extroverts and introverts [10]. Other authors note the following characteristics of creatively gifted ones: self-discipline in work, ability to delay pleasure, perseverance in situations of frustration, independence of judgments, high autonomy, risk appetite, tolerance for uncertainty, integral locus of control, absence of sexual stereotypes, perfectionism and a high level of self-initialization [11].

R.B. Cattell argues that creatively gifted people of science and art are characterized by schizotymia, radicalism, domination and introversion [12]. These signs may indicate a variety of manifestations of giftedness. It should be borne in mind that gifted children not only display their abilities in different ways, but sometimes prefer not to show them at all for a number of reasons independent of giftedness. These include, among other things, the following: the desire to maintain close relationships with peers, not to cause their jealousy and vigilance, to be like everyone else, not to stand out.

The question naturally arises of the characteristics of potentially gifted children. The authors of the American multi-year state program for the early rehabilitation and acceleration of gifted preschool children with sensory or physical disabilities (RAPYD 1) attempted to answer this question. The data obtained as a result of their research allowed to determine the range of areas (spheres) of giftedness in which children demonstrate high achievements and (or) potential opportunities. Such spheres were six: the intellectual and motor spheres, the field of academic achievement, creative or productive thinking, communication and leadership, artistic activity. This list is recognized as a finite by a number of authorities in the field of giftedness, and the proposed scheme is useful and applicable to various categories of gifted children [13]. In these areas gifted children have significant advantages over their peers. They learn more easily and better grasp the material, are more adapted emotionally and socially, have leadership qualities, are initiative, are creative, demonstrate a good level of development of basic motor skills and physical strength, are curious, persistent, active. The main conclusion is that these children are unique not only in the level of their achievements in one or several spheres, but also in the process of their development and in the results of their activities.

Similar conclusions were reached by K.A. Heller and his colleagues who experimentally proved that with a certain interaction of internal (personal) characteristics and external factors (social environment) talented children develop a potential that leads to outstanding achievements in one of the following areas: sports, languages, science, art, technology, abstract thinking, mathematics, social relations. Indicators of giftedness, in their opinion, are intellect, creativity, social competence, psychomotor and practical abilities, musicality as an integral part of giftedness in the field of art [14]. They are independent parts of giftedness, which confirms the hypothesis about specific areas of its application.

The most successful in this model of giftedness was the principle of distinction and separate interpretation:

a) Giftedness as a complex of characteristics acquired by a child under the influence of certain environmental conditions,

b) The achievements of this child as a sphere of successful implementation, application, use of this giftedness.

This allowed to outline the grounds for looking for intragroup differences of gifted children, while, as noted, giftedness appears to be extremely diverse and individualized.

\section{ANALYSIS OF INTRAGROUP DIFFERENCES OF GIFTED CHILDREN}

The criteria of intragroup differences were the most significant indicators of giftedness (the level of intelligence and creativity), the conditions of the environment and their characteristics (parents' educational level, the number of siblings and the order of their birth, the school atmosphere, the experience of success and failures, etc.) as well as personality characteristics typical of gifted students who achieved the greatest success (motivation for achievement, hope for success, readiness to exert efforts, locus of control, a thirst for knowledge, ability to cope with the task, selfevaluation). Gifted students were divided into 4 groups, which differed in the degree of giftedness (it was determined by the intensity of intelligence, creativity): gifted (6-10\% of the age group), normally gifted (5-6\%), highly gifted (3-5\%), extremely highly gifted $(1-3 \%)$. In quantitative terms, the last two groups differ little. Qualitative differences are noteworthy. Highly talented students have a higher academic self-esteem and stability of the quality of thinking. They show lower values on the scales of external causal attribution, planning and organization of work, the locus of control and interaction with peers. All other indicators, namely: anxiety in testing and general anxiety, attention control, a thirst for knowledge - differ slightly. Virtually there were no differences in the general, non-academic self-esteem.

Another criterion is achievement of success. Gifted students were divided into groups of "successful" and "unsuccessful" on the basis of the correspondence of their achievements to the level of abilities. Both groups of gifted high school students, for example, had differences, primarily in terms of personal characteristics: the first group had significantly higher academic self-esteem, a hope for success, stability of the quality of thinking. Somewhat lower in the group of "unsuccessful" students were the indicators of overall self-esteem, planning and organization of work, control of motivation, thirst for knowledge, but they demonstrate higher anxiety in testing and general anxiety, anxiety about school assessments. Virtually there were no differences in the control of attention and cooperation with 
peers. According to other studies, these results are confirmed in other samples of gifted children, which indicates the stability of these characteristics [15].

Some specifications were made based on the results of the Moscow longitudinal study of mentally gifted high school students who had relatively poor academic success [16]. In the absence of significant differences in cognitive characteristics, these students demonstrated a greater degree of destructive tendencies in motivational and personal development (low self-esteem, fear of failure, high anxiety, instability in stress), which adversely affects the development of giftedness. In addition, this group of gifted children is extremely ambiguous, has many variants of combining personal characteristics, which makes it difficult to find the reasons for failures and, consequently, to help these students. Besides, these children should be studied only in comparison with the same gifted ones, which enriches the psychology of giftedness in describing individual variants of its manifestation.

These data were supplemented by the results of an analysis of the intragroup differences of gifted children, depending on their gender [17] [18] [19] [20]. In one of the longitudinal studies it was found that gifted boys showed higher results in the tests of mathematical judgments, spatial thinking and mechanics [21]. In the field of interest, boys preferred mathematics, physics and engineering, in which, by the way, they achieved the greatest success by the age of 23. Girls were characterized by more equal and balanced interests, and they chose mainly professions in the field of social and aesthetic sciences. The same features were noted as a result of annual testing in the US in 1988. Gifted girls showed a clear advantage over young men only in their native language, but in mathematics and natural sciences young men achieve the highest results in 3 and 5 times respectively more than the girls with the same indicators [22]. There are data that girls choose fewer courses in mathematics, chemistry, physics, or prefer light-weight versions of these courses, which does not contribute to early involvement in the future profession and limits the possibilities of their choice in the field of natural and mathematical sciences [23] [24]. According to the results of the Munich longitudinal study, adolescent girls lagged behind the boys in the field of computer technology, but outnumbered in the verbal field and in the processing of information [25]. They had the best results in all school subjects, except mathematics and physics, were more active in the field of music and drawing, but rarely participated in classes with technology and science.

As for the personal characteristics of gifted girls, they are more prone to fear of failure, they are more influenced by surrounding people, have a higher social adaptation, which affects their self-esteem and can lead to self-abasement. L. Terman and M. Oden cite the data that gifted girls are taller, physically stronger and healthier than their peers, but feel physically less developed than boys, including the gifted ones [26]. Moreover, certain age-specific features of sexual socialization of gifted boys and girls have emerged. Thus, due to faster maturation and development of girls, their giftedness manifests itself earlier [27]. It is reasonable to assume that this advantage at an earlier age creates additional opportunities that favor the development of their giftedness. However, according to E.E. Maccoby, C.N. Jacklin; C.P. Bendow; A.C. Huston; Heller, as the girls grow up or the length of their studies increases, the "scissors effect" takes place, that is, the deterioration of the results in terms of intelligence, creativity, psychomotor talent, and social competence [28] [29] [30] [31]. In adolescence, gifted children often experience anxiety and insecurity: in place of the need for achievements and high self-esteem comes the desire for popularity, the need for love, friendship, belonging to the group. And in fact, as a child, these girls for a long time were alone while they studied and in the field of interests they were closer with gifted boys, they participated in traditionally "male" occupations and, in general, excelled boys in achievements in all subjects. The attitude of the girls to their own giftedness also changes: they begin to see in it "uncomfortable" moments as well, which separate them from friends, create difficulties in the emerging sympathies. Researchers note at this age the first signs of concealment, disguise of giftedness in girls. Thus, L. Silverman cites the data on reducing the number of gifted girls from $1 / 2$ in primary school to $1 / 3$ in high school from all gifted children [32].

So, sex differences are reflected not only in the academic and professional success of gifted children, they are also revealed in the manifestations of giftedness in children of different age.

The following changes were observed in the field of cognitive endowment. In primary school, the intellectual abilities of gifted children differed significantly from the average age, during adolescence these differences somewhat decreased, and in older students they reached the same level. In the 9th-11th grades, the number of gifted students who have improved their intellectual abilities is increasing, and quite often cases of the decline of these abilities, which took place in junior and middle school, almost never occur.

As for creativity, the picture here is somewhat different: there were no significant differences in the first three years of education of pupils, who were assigned to the gifted group, at the middle school age these differences were more stable, later they practically disappeared, possibly as a consequence of age equalization in the development of creativity or the influence of school socialization. Especially noticeable is the decrease in creativity in high school mathematicians, but the advantage over peers remains due to originality. This age group of gifted students is characterized by a decrease in the number of verbally creative ones.

There are no differences between the sexes, but there are differences between gifted mathematics students and humanitarians in terms of the profile of abilities, achievements and extracurricular activities. Presumably, these differences are related to the specifics of training programs in special subjects, the tightening of requirements for these subjects. In extracurricular activities, mathematicians are more engaged in sports, natural sciences, music, while the humanitarians do more literature, theater, and the interests of the first group of gifted high school 
students are most clearly shaped only by the last year of education, while the humanitarians identify their likings much earlier, in the 9th grade. If we compare these data with secondary schoolchildren, the picture is as follows: from grades 7-9 the gifted showed more stable and active interest in social activities and music, theater, literature and art than in the natural sciences, which is characteristic of them in 911 grades. In the field of motivation of educational achievements, middle and senior gifted schoolchildren had a clear advantage over peers in the indicators of hope for success [33][34].

\section{CONCLUSION}

The data presented indicate that the group of gifted children is extremely heterogeneous. Heterogeneity is manifested in qualitative and quantitative differences in the factors of giftedness (intellect, creativity, social competence, artistic and psychomotor abilities) and in the fields of its application. Attempts to describe gifted children often run into difficulties caused by the inseparability of the individual and age lines of development. Despite available in our country materials devoted to the identification of individualtypical phenomena of giftedness in junior, middle and senior school children, the question of the realization of giftedness in the future is still open, since the changes in giftedness can be correlated with any environmental factor, they can combine with personal characteristics in a wide variety of options. The analysis shows that to create a typical psychological portrait of a gifted child is a matter of exceptional importance and complexity at the same time. Implementation of this goal requires the use of nontraditional approaches and solutions.

\section{REFERENCES}

[1] M.L. Bagramyants, Psychology of giftedness: theory, experiment, practice (textbook). 2-nd ed, revised and enlarged. Moscow: MSTU MAMI, 2008.

[2] Psychology of giftedness of children and adolescents / Ed. N.S.Leites. M: Publishing center "Academy", 1996.

[3] K.A. Heller, K. Perlet, V. Siervald, Longitudinal study of giftedness // Questions of psychology. 1991. No. 2, pp. 120-127.

[4] M.L. Ivleva, V.Yu. Ivlev, Principal approaches of modern psychology to constructing giftedness // "Proceedings of the 2017 2nd International Conference on Contemporary Education, Social Sciences and Humanities". (ICCESSH 2017). Part of the series ASSEHR. Moscow, Russia, 2017, v.124, pp. 11761180.

[5] A.M. Matyushkin, Mysteries of giftedness. Problems of practical diagnostics. M: School-press. 1993.

[6] C. Takacs, They don't get gifted until the fourth grade: what parents can do until then // Roeper Review. No. 4, pp. 43-45.

[7] E.I. Shcheblanova, Features of cognitive and motivational and personal development of gifted senior pupils // Questions of psychology. 1999, No. 6, pp. 36-47.

[8] J.S. Renzulli, The three-ring conception of giftedness: A developmental model for creative productivity // Sternberg R.I., Davidson J.E. (eds.). Conceptions of giftedness. Cambridge: Cambr. Univ. Press, 1986, pp. 53-92.

[9] L. Terman, M.Oden, Genetic Studies of Genius // The gifted child grows up. Stanford CA: Stanford University Press, 1959.
[10] M. Chikszentmihalyi, Society, culture and person: A system view of creativity // R. Stemberg, T. Tardiff (eds.). The nature of creativity. Cambridge: Cambridge Press. 1988, pp. 339-352.

[11] T.M. Amabile, M.A. Collins, Creative // Manstead A.S.R., Hewstone M. (eds.). The Blackwell encyclopedia of social psychology. Oxford: Blackwell Publ. 1996, pp. 142-144.

[12] R.B. Cattell, Personality \& learning theory. N.-Y.: Spring, 1979.

[13] M. Karnes and Associates, Preschool talent checklists manual. Urbana Il.: Publication Office, Institute for Child Behavior \& Development. 1978.

[14] K.A. Heller, K. Perlet, V. Siervald, Longitudinal study of giftedness // Questions of psychology. 1991. No. 2, pp. 120-127.

[15] N. Butler-Por, Underachievers in school: issues \& intervention. Chichester: John Wiley \& Sons. 1987

[16] E.I. Shcheblanova, Features of cognitive and motivational and personal development of gifted senior pupils // Questions of psychology. 1999, No 6, pp. 36-47.

[17] K.A. Heller, Evaluation of the programs for the gifted // M.W. Katzko, F.J. Monks (eds.). Nurturing talent, individual needs \& social ability. The 4th conference of ECHA. Assen: Van Gorcum. 1995, pp. 264268.

[18] C.P. Bendow, Sex differences in mathematical reasoning ability in intellectually talented preadolescents: Their nature. Effects \& possible cause // Behav. \& Brain Sciences. 1988. No. 11, pp. 169-232.

[19] A.C. Huston. Sex-typing // Musson P.H. (ed.) Handbook of child psychology. V.4. N.-Y.: Wiley. 1983

[20] E.E. Maccoby, C.N. Jacklin, The psychology of sex differences. Stanford: Stanford University Press, 1974

[21] D. Lubinski, C.P. Bendow, The study of mathematically precocious youth: the first 3 decades of a planned 50-year study of intellectual talent // Subotnik R.F., Arnold K.D. (eds.). Beyond Terman: contemporary longitudinal studies of giftedness \& talent. Norwood. 1994, pp. 255-281.

[22] B.A. Kerr, N. Colangelo, College plans of academically talented students / J. Of Counseling \& Development. 1988. No. 32, pp. 245248.

[23] J.F. Feldhusen, C. Willard-Holt, Gender differences in classroom interactions \& career aspirations of gifted students // Contemporary Educ. Psychol. 1992, V.18, pp. 355-362.

[24] M. Delcourt, Characteristics of high-level creative productivity: A longitudinal study of students identified by Renzulli`s Three-Ring Conception of Giftedness // Subotnik R.F., Arnold K.D. (eds.) Beyond Terman: contemporary longitudinal studies of giftedness \& talent. Norwood. 1994, pp. 401-436.

[25] K.A. Heller, K. Perlet, V. Siervald, Longitudinal study of giftedness // Questions of psychology. 1991. No. 2, pp. 120-127.

[26] L. Terman, M. Oden, Genetic Studies of Genius // The gifted child grows up. Stanford CA: Stanford University Press, 1959.

[27] B.A. Kerr, N. Colangelo, College plans of academically talented students / J. Of Counseling \& Development. 1988, No. 32, pp. 245 248.

[28] E.E. Maccoby, C.N. Jacklin, The psychology of sex differences Stanford: Stanford University Press, 1974.

[29] C.P. Bendow, Sex differences in mathematical reasoning ability in intellectually talented preadolescents: Their nature. Effects \& possible cause // Behav. \& Brain Sciences, 1988, No. 11, pp. 169-232.

[30] A.C. Huston, Sex-typing // Musson P.H. (ed.) Handbook of child psychology. V.4. N.-Y.: Wiley. 1983

[31] K.A. Heller, Evaluation of the programs for the gifted // M.W.Katzko, F.J. Monks (eds.). Nurturing talent, individual needs \& social ability. The 4th conference of ECHA. Assen: Van Gorcum, 1995 pp. 264-268

[32] L. Silverman, The search for giftedness // Gifted Education Press Quarterly. Joan Smutny, Jim Delisle, Susan Winebrenner, James Carroll (eds.): Gifted education Press of Manassas, Virginia. The spring 1998. 
[33] E.I. Shcheblanova, Features of cognitive and motivational and personal development of gifted senior pupils // Questions of psychology, 1999, No. 6, pp. 36-47.

[34] O.V. Chistyakova. Humanitarian-anthropological aspects of contemporary education (philosophical analysis) // Proceedings of the 3rd International Conference on Arts, Design and Contemporary Education (ICADCE 2017). Vol. 144. Moscow, Russia. 29-30, May, 2017. Paris: Atlantis Press, 2017, pp. 610-613. 